\title{
DETERMINATION OF HIGH RESOLUTION PORE WATER PROFILES OF TRACE METALS IN SEDIMENTS OF THE RUPEL RIVER (BELGIUM) USING DET (DIFFUSIVE EQUILIBRIUM IN THIN FILMS) AND DGT (DIFFUSIVE GRADIENTS IN THIN FILMS) TECHNIQUES
}

\author{
M. LEERMAKERS ${ }^{1, *}$, Y. GAO ${ }^{1}$, C. GABELLE ${ }^{2}$, S. LOJEN $^{3}$, B. OUDDANE, \\ M. WARTEL ${ }^{2}$ and W. BAEYENS ${ }^{1}$ \\ ${ }^{1}$ Department of Analytical and Environmental Chemistry, Vrije Universiteit Brussel, Pleinlaan 2, \\ 1050 Brussels, Belgium; ${ }^{2}$ Laboratoire de Chimie Analytique et Marine, ELICO (UMR CNRS 8013), \\ Université des Sciences et Technologies de Lille, Bât C8 (2ème étage), 59655 Villeneuve d'Ascq \\ Cedex, France; ${ }^{3}$ J. Stefan Institute, Department of Environmental Science, Lubjiana, Slovenia \\ (*author for correspondence, e-mail: mleermak@vub.ac.be, Tel: +3226293266; \\ Fax: +3226293274)
}

(Received 14 February 2005; accepted 28 April 2005)

\begin{abstract}
The techniques of diffusional equilibrium in thin films (DET) and diffusional gradients in thin films (DGT) were used to obtain high resolution pore water profiles of total dissolved and labile trace (mobilizable) metals in the sediments of the Rupel River, Belgium. DGT measures labile metal species in situ by immobilizing them on a resin gel after diffusion through a diffusive gel whereas for DET an equilibrium is established between the DET gel and the pore water. Concentrations of $\mathrm{Pb}$ and $\mathrm{Zn}$ obtained by DGT were in good agreement with the results obtained by centrifugation, and thus were well buffered by rapid equilibrium with the solid phase, whereas $\mathrm{Fe}, \mathrm{Mn}$ and $\mathrm{Cd}$ were very tightly bound to the sediment phase and large differences were observed between the labile and the total metal concentrations. $\mathrm{Cu}, \mathrm{Zn}, \mathrm{Co}$ and $\mathrm{Ni}$ show intermediated behavior.

Good correlations were found between the profiles of As and Fe and Mn and Co for DET as well as DGT showing a close link between the geochemical behavior of these elements. $\mathrm{Cu}, \mathrm{Zn}, \mathrm{Pb}$ and $\mathrm{Cd}$ are also influenced by the reductive mobilization of $\mathrm{Fe}$ and $\mathrm{Mn}$ oxides but are also closely linked to the bacterial degradation of organic matter in the surface sediments as to the precipitation of metal sulfides in the deeper layers.
\end{abstract}

Keywords: trace metals, chemical speciation, DGT, DET, pore water, sediments

\section{Introduction}

Diagenetic processes in sediments induce sharp gradients of redox elements and trace metals in sediment pore waters. An understanding of the biogeochemical behavior and mobility of metals in sediments requires the determination of high resolution vertical profiles of trace metals in pore waters.

In recent years techniques such as DET (Diffusive Equilibrium in Thin Films) and DGT (Diffusive Gradients in Thin Films) have become increasingly popular for the determination of trace metals, major ions and nutrients in sediment pore water (Davison et al., 1991; Zhang et al., 1995; Docekalova et al., 2002; Fones et al., 2004). 
The recently developed technique of diffusive equilibrium in thin films known as DET (Davison et al., 1991) is similar to dialysis, but the sampling medium is a hydrogel instead of a solution retained by a dialysis membrane. As for dialysis, solutes equilibrate within the solution held in the sampler (the hydrogel is typically 95\% water). The collected species depend on the pore size of the outer membrane and the hydrogel itself. Equilibrium concentrations of solutes are measurement for sufficiently long deployment times. In the DET technique using constrained probes, metals diffuse from the pore water into small strips (1 mm intervals) of agarose gel until equilibrium with the pore water is reached. With this technique no preconcentration is obtained, nor a selection of compounds as long as the pore size allows diffusion. This technique thus provides information on the total dissolved species concentration.

In the technique of diffusive gradients in thin films (DGT) developed by Zhang and Davison (1995), an acrylamide diffusive gel is backed by a resin gel (Chelex) which binds (trace) metals. The technique of DGT separates species kinetically and does not depend on equilibrium. Solutes diffuse freely through a layer of hydrogel and are then immobilized in an underlying layer of binding agent. The device is deployed for a fixed period of time and then the mass of accumulation solute in the binding layer is measured. For a know thickness of the diffusion layer $(\Delta \mathrm{g})$, the mean concentration in solution can be calculated using Fick's law (Equation 1).

$$
F=D \cdot \frac{d c}{d x}=\frac{D \cdot c_{b}}{\Delta g}
$$

where $(D)$ is diffusive coefficient of solute in diffusive gel, $\left(c_{b}\right)$ is concentration of solutes in bulk solution (pore water) and $(\Delta g)$ thickness of diffusive gel.

The flux of metals can be also defined as mass of metals $(M)$, which diffuse through the diffusive gel with surface area $(A)$ during the deployment time $(t)$. If the mass of solutes in resin gel is measured after deployment of DGT device using appropriate analytical method (Zhang and Davison, 1995; Davison et al., 1997), concentration $\left(c_{b}\right)$ can be calculated from Equation 2 .

$$
c_{b}=\frac{M \cdot \Delta g}{D \cdot A \cdot t}
$$

In practice, the concentration gradient within the diffusive gel is often not constant during the deployment time of the DGT probe in sediment. Concentration $c_{b}$ changes with time (Zhang et al., 1995) and DGT measured concentration is than interpreted as time-average value of $c_{b}$.

$$
c_{\text {DGT }}=\frac{1}{t} \int_{t=0}^{t} c_{b}\left(t_{i}\right) \mathrm{d} t
$$


When two DGT probes are deployment with different gel thicknesses $\left(\Delta g_{1}\right.$ and $\Delta g_{2}$ ) for the same period of time it is possible to obtain information about the resupply of metals from the solid phase. From Equation (2) we obtain 2 concentrations $C_{b 1}$ and $C_{b 2}$. If the resupply of metals from the solid phase is sufficient to maintain the maximum flux (fully sustained case), then $C_{b 1}=C_{b 2}$. In the partially sustained case, the concentration using the thinner gel (which requires a higher flux)will be underestimated. If there is no resupply from the solid phase (unsustained case), the concentration gradient is mainly within the sediment, minimising the effect of the diffusive gel. In that case $F\left(\Delta g_{1}\right)=F\left(\Delta g_{2}\right)$ and $\Delta g_{1} / \Delta g_{2}=C_{b 2} / C_{b 1}$ (Zhang and Davison, 1995).

Separation of species depends on both chemical availability (lability) and pore size of species. Since the technique relies on diffusion of ions through a narrowpore hydrogel and the affinity of the metals for the Chelex gel, only labile metals will be trapped and measured. Thus combining both DET and DGT techniques information on the speciation of the metals can thus be obtained.

\section{Methods and Materials}

\section{SAMPLING SITE}

The Rupel River is a tributary of the Schelde River, originating at the confluence of the Dijle end the Nete and joining the Schelde in Rupelmonde (Figure 1). It receives a large amount of organic matter inputs through the River Zenne, which transports untreated wastewaters from the city of Brussels. The Rupel River is a tidal river, with tidal heights of about $5 \mathrm{~m}$. Sediments were collected on an intertidal flat near the town of Willebroek.

\section{SAMPLING AND HANDLING PROCEDURES}

Sediment cores were collected from the Rupel River in Belgium in April 2003. The samples were collected from an intertidal flat at low tide. Plexiglass tubes and rubber stoppers were used for collection. The cores were retrieved by hand allowing some overlying water to remain above the sediment. Sampling was performed by both the research groups of the Vrije Universiteit Brussel (VUB) and the Université de Science et Technologie de Lille (USTL) group. The DET and DGT techniques were performed by both groups, allowing an interlaboratory intercomparison. The two groups sampled a few meters away from each other.

Redox and $\mathrm{pH}$ measurements were performed on site. One of the tubes had pre-drilled holes at $1 \mathrm{~cm}$ intervals which had been covered with tape for collection of the sediment. The tape was punctured and the electrode inserted.

Sectioning of the cores for analysis of the pore water by centrifugation was performed in a glove bag under nitrogen atmosphere. After centrifugation, the 


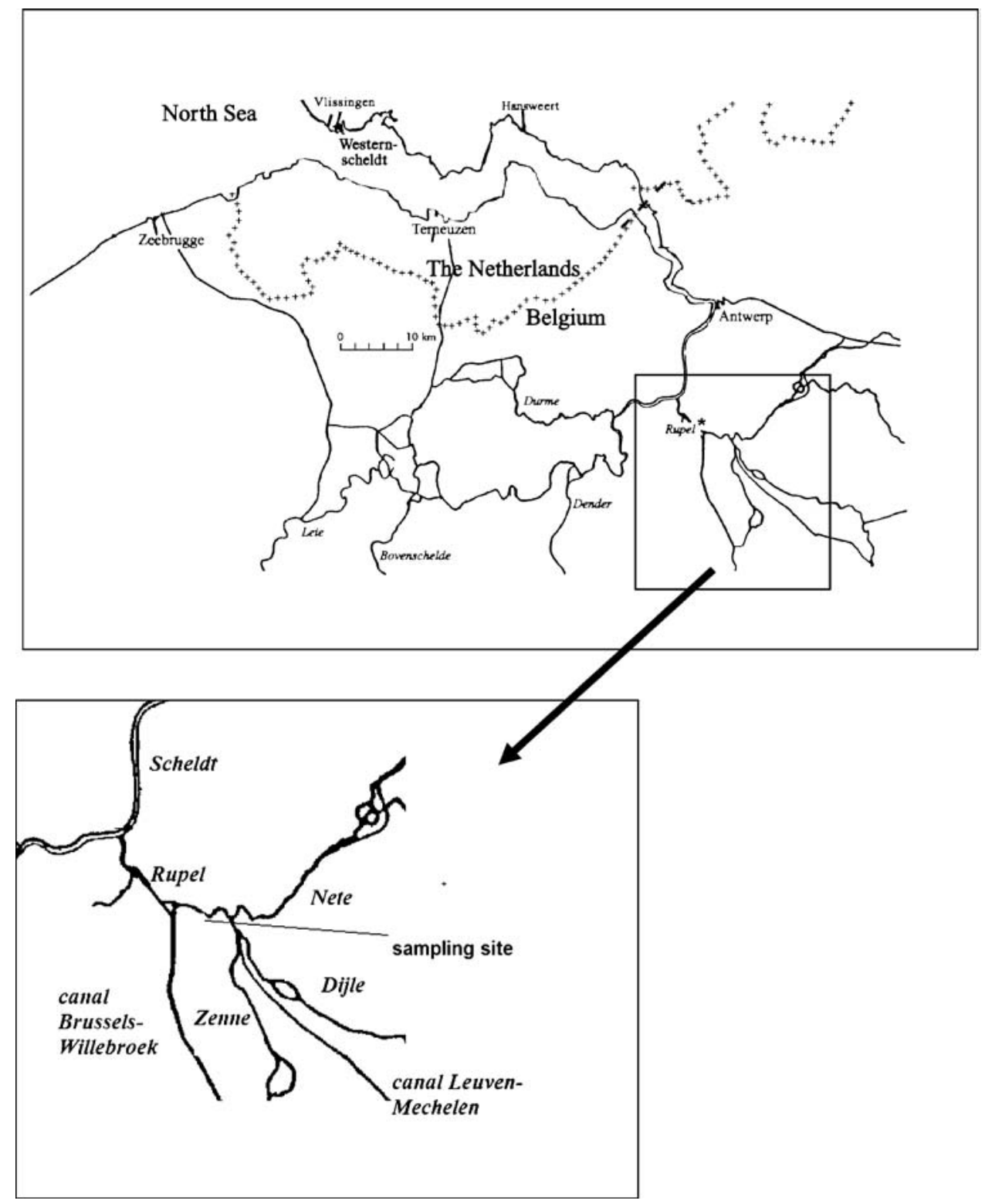

Figure 1. Location of the sampling station on the River Rupel.

pore water was filtered through a $0.45 \mu \mathrm{m}$ cellulose acetate disposable filter. This filtration was performed in a glove bag under nitrogen atmosphere.

The DGT probes (DGT Research Ltd.) were $180 \mathrm{~mm} * 40 \mathrm{~mm}$, with a window of $150 \mathrm{~mm} * 18 \mathrm{~mm}$ open to the sediment. A $0.45 \mu \mathrm{m}$ cellulose acetate filter (Millipore) separated the gels from the sediment. An agarose-polyacrylamide 
hydrogel comprising of $15 \%$ acrylamide (Merck) and $0.3 \%$ agarose derived cross linker (DGT Research Ltd.) was used as a diffusive gel. Two different gel thicknesses were used, $0.8 \mu \mathrm{m}$ and $1.2 \mu \mathrm{m}$. Ion exchange resin (Chelex 100) with a bead size of 200-400 Mesh (BioRad) impregnated in a thin gel (0.4 mm thickness) was used as the binding layer. The preparation of the resin and diffusive gel was performed as described by Zhang and Davison (1995).

The constrained DET probes (DET technologies Ltd) were $180 \mathrm{~mm} * 40 \mathrm{~mm}$, with a window of $150 \mathrm{~mm} * 18 \mathrm{~mm}$ open to the sediment and consist of $751 \mathrm{~mm}$ slits with a $1 \mathrm{~mm}$ interval between the slits. The slits were filled with agarose gel (1.5\%) prepared as described by DGT Research Ltd (www.dgtresearch.com).

Prior to deployment, the entire DET gel assemblies were de-oxygenated by immersing them for 24 hours in a container filled with deionized water and bubbling with nitrogen. DGT probes were deoxygenated for $24 \mathrm{~h}$ in a container filled with precleaned (using Chelex 100) $\mathrm{NaCl}(0.1 \%)$.

The cores for deployment of the DET and DGT probes were taken back to the lab. Deployment was performed at room temperature for 24 hours deployment times. Core A and core B (VUB) contained one DGT and one DET probe placed back to back. Core C (USTL) contained 2 DGT probes placed back to back with different diffusive gel thickness $(0.8$ and $1.2 \mathrm{~mm})$ and core D (USTL) contained one DET probe.

In the lab all manipulations of the gels were carried out in a laminar flow hood in a clean room. The DGT probes were opened, the filter and diffusive gel removed and the resin gel was cut in $5 \mathrm{~mm}$ intervals using a Plexi gel cutter. Each gel slice was eluted in $1 \mathrm{ml} 1 \mathrm{~N} \mathrm{HNO} 3$ for $24 \mathrm{~h}$ and further diluted to $10 \mathrm{ml}$ for analysis by ICPMS. In (1ppb) was added as internal standard.

DET gels (typically $20 \mu \mathrm{l}$ ) were transferred preweighed $2 \mathrm{ml}$ tubes, were weighed and were eluted in $1 \mathrm{ml} 1 \mathrm{~N}$ HNO3. They were generally not diluted further for analysis.

Blank DET and DGT probes underwent all steps apart from deployment, including casting, probe construction, deoxygenation. They were treated in the same way as the sample probes. The DGT probe was sliced in $325 \mathrm{~mm}$ intervals, 10 slices were randomly chosen for analysis. For the DET probe 10 slices were randomly chosen from the 75 blanc slices for analysis.

A High Resolution Inductively Coupled Mass Spectrometry (HR-ICPMS) (Thermo Finnigan Element II) was used to determine the concentrations of the elements $\mathrm{As}, \mathrm{Cd}, \mathrm{Co}, \mathrm{Cu}, \mathrm{Fe}, \mathrm{Mn}, \mathrm{Ni}, \mathrm{Pb}$ and $\mathrm{Zn}$ by the VUB. USTL used a Thermo Elemental X7 Series ICPMS for the analysis of $\mathrm{Cd}, \mathrm{Co}, \mathrm{Cr}, \mathrm{Cu}, \mathrm{Mn}, \mathrm{Ni}$, $\mathrm{Pb}$ and $\mathrm{Zn}$.

Metals in sediments were analyzed by HR-ICPMS (Thermo Finnigan Element II) after aqua regia digestion in a microwave oven (CEM Mars 5).

All manipulations related to extraction of sedimentary $\mathrm{S}$ species were performed in an $\mathrm{N}_{2}$-filled glove bag or in tightly closed vessels to prevent the oxidation. Sedimentary sulfides were extracted as two phases - acid volatile sulfide (hereafter 
referred to as AVS), consisting mainly of amorphous FeS, poorly crystallized greigite and/or mackinavite (Billon et al., 2001), and Cr reducible sulfide (CRS), consisting of pyrite and elemental S. AVS and CRS were isolated from untreated wet sediment using sequential extraction procedure described by Canfield et al. (1986) and modified by Billon et al. (2001, 2001a). Briefly, AVS was decomposed by addition of $6 \mathrm{~N} \mathrm{HCl}$ and the deliberated $\mathrm{H}_{2} \mathrm{~S}$ was trapped in an alkaline antioxidant solution (0.2 M Na-EDTA in $2 \mathrm{M} \mathrm{NaOH})$. After the decomposition of AVS was completed, the $\mathrm{CrCl}_{2}$ was added and the suspension was kept at boiling temperature to decompose pyrite and elemental sulfur. Concentrations of AVS and CRS were determined as $\mathrm{S}^{2-}$ concentration in the antioxidant solutions by potentiometric titration (Metrohm 736 GP Titrino system) and recalculated to $S$ concentration in dry sediment. The reproducibility of the analysis was $\pm 2 \%$ and the reproducibility of the whole procedure was determined to be better than $\pm 8 \%$, due to the natural heterogeneity of the sediment (Billon et al., 2001).

Prior to the extraction of elemental S, humic and fulvic acids, the wet sediment was washed in deaerated $0.5 \mathrm{M} \mathrm{NaCl}$ to remove dissolved sulfate and sulfide. Dissolved sulfide was then precipitated from the filtered solution $(0.45 \mu \mathrm{m})$ by addition of deaerated $10 \% \mathrm{Zn}$ acetate solution and the precipitate was further treated as AVS. Dissolved sulfate was precipitated from the residual solution by addition of $\mathrm{BaCl}_{2}$ solution and its concentration was determined gravimetrically (Standard methods, 1998). Sulfur bond to humic and fulvic acids (hereafter referred to as HAS and FAS, respectively) were extracted by digestion of the sediment in $0.1 \mathrm{~N}$ $\mathrm{NaOH}$ solution (Brüchert and Pratt, 1996; Henneke et al., 1997).

Elemental $\mathrm{S}$ was extracted in a methanol-toluene mixture (3:1). The filtered solution was evaporated and the residue was further treated as CRS.

Humic and fulvic acids were extracted in a $0.1 \mathrm{~N} \mathrm{NaOH}$ solution. Humic acids were precipitated by addition of $\mathrm{HCl}$ to $\mathrm{pH}<2$ to the solution. Precipitate was washed, dried, decomposed in Parr bomb (Oxygen bomb 1108, John Morris Scientific) and $\mathrm{S}$ bound to humic acids (HAS) was precipitated as $\mathrm{BaSO} 4$ by addition of $\mathrm{BaCl} 2$ solution. The residual solution after removal of precipitated humic acids was evaporated to $<20 \%$ of initial volume and $\mathrm{H}_{2} \mathrm{O}_{2}$ was added to oxidize the $\mathrm{S}$ bound to fulvic acids (FAS) to sulfate, which was then precipitated as $\mathrm{BaSO}_{4}$ (Brïchert and Pratt, 1996).

\section{Results and Discussion}

\section{RESULTS}

\section{Detection Limits}

DGT blanks are expressed both in $\mathrm{ng} / \mathrm{cm}^{2}$ and in $\mu \mathrm{g} / \mathrm{L}$ (Tables I and II). The latter were calculated using the same deployment time as the probes in the sediments $(24 \mathrm{~h})$. Detection limits were calculated as 3 times the standard deviation of the blanks. The measured concentrations in the samples were well above the 
TABLE I

Blanks and detection limits for the DGT gels (lab VUB)

\begin{tabular}{lclll}
\hline Element & $\begin{array}{l}\text { DGT blank } \\
\left(\mathrm{ng} / \mathrm{cm}^{2}\right)\end{array}$ & $\begin{array}{l}\text { DGT blank } \\
(\mu \mathrm{g} / \mathrm{L})\end{array}$ & $\begin{array}{l}\text { Detection } \\
\text { limit }(\mu \mathrm{g} / \mathrm{L})\end{array}$ & $\begin{array}{l}\text { Measured } \\
\text { range }(\mu \mathrm{g} / \mathrm{L})\end{array}$ \\
\hline $\mathrm{Cd}$ & $0.017 \pm 0.006$ & $0.004 \pm 0.001$ & 0.003 & $0.006-0.1$ \\
$\mathrm{~Pb}$ & $0.43 \pm 0.21$ & $0.070 \pm 0.034$ & 0.010 & $0.1-13$ \\
$\mathrm{Mn}$ & $0.35 \pm 0.24$ & $0.076 \pm 0.054$ & 0.16 & $66-176$ \\
$\mathrm{Fe}$ & $4.9 \pm 3$ & $1.019 \pm 0.771$ & 23 & $1000-18000$ \\
$\mathrm{Co}$ & $0.019 \pm 0.009$ & $0.004 \pm 0.002$ & 0.001 & $0.3-9$ \\
$\mathrm{Ni}$ & $3.16 \pm 1.13$ & $0.69 \pm 0.25$ & 0.24 & $0.4-7$ \\
$\mathrm{Cu}$ & $0.73 \pm 0.29$ & $0.15 \pm 0.06$ & 0.09 & $0.2-3$ \\
$\mathrm{Zn}$ & $16 \pm 4$ & $3.3 \pm 0.9$ & 2.5 & $0.8-237$ \\
\hline
\end{tabular}

TABLE II

Blanks and detection limits for the DGT gels (lab USTL)

\begin{tabular}{lcclc}
\hline Element & $\begin{array}{l}\text { DGT blank } \\
\left(\mathrm{ng} / \mathrm{cm}^{2}\right)\end{array}$ & $\begin{array}{l}\text { DGT blank } \\
(\mu \mathrm{g} / \mathrm{L})\end{array}$ & $\begin{array}{l}\text { Detection limit } \\
(\mu \mathrm{g} / \mathrm{L})\end{array}$ & $\begin{array}{l}\text { Measured range } \\
(\mu \mathrm{g} / \mathrm{L})\end{array}$ \\
\hline $\mathrm{Cd}$ & $0.02 \pm 0.009$ & $0.004 \pm 0.001$ & 0.003 & $0.015-0.13$ \\
$\mathrm{~Pb}$ & $0.40 \pm 0.1$ & $0.06 \pm 0.016$ & 0.048 & $0.15-1.2$ \\
$\mathrm{Co}$ & $0.029 \pm 0.007$ & $0.006 \pm 0.001$ & 0.003 & $1.4-6.3$ \\
$\mathrm{Ni}$ & $2.96 \pm 1.4$ & $0.63 \pm 0.3$ & 0.9 & $2-8.8$ \\
$\mathrm{Cu}$ & $2.73 \pm 0.46$ & $0.54 \pm 0.09$ & 0.27 & $0.5-2$ \\
$\mathrm{Zn}$ & $12.2 \pm 4$ & $2.47 \pm 0.8$ & 2.4 & $9-34$ \\
\hline
\end{tabular}

detection limits except for $\mathrm{Cd}$, were some levels were around the detection limit (Table I).

DET blanks were calculated taking the dilution factor into account (Tables III and IV). As the result of the high blanks of the agarose gel for certain elements and important dilution factor (around 50) only the concentrations of Fe, Mn, As and $\mathrm{Co}$ were al least ten times higher than the detection limit. $\mathrm{Cd}$ and $\mathrm{Pb}$ could also be determined, with $\pm 20 \%$ of the samples in the range of the detection limit. For $\mathrm{Cu}$, $\mathrm{Zn}$ and $\mathrm{Ni}$ approximately $40 \%$ of the samples are below the detection limit.

\section{Characterisation of the Rupel Sediments}

The redox potential shows negative values just below the sediment water interface and remains fairly constant with depth (Figure 2). Sulfate concentration dropped from 0.65 to $0.05 \mathrm{mM} / \mathrm{L}$ in the upper $2 \mathrm{~cm}$ and was exhausted in a depth of $7 \mathrm{~cm}$. Dissolved sulfide significantly increased with depth, reaching up to 1.9 $\mathrm{mM} / \mathrm{L}-$ a concentration, which exceeds the dissolved sulfate at the sediment/water surface. 
TABLE III

Blanks and detection limits for the DET gels (lab VUB)

\begin{tabular}{lcll}
\hline Element & $\begin{array}{l}\text { DET blank } \\
(\mu \mathrm{g} / \mathrm{L})\end{array}$ & $\begin{array}{l}\text { Detection } \\
\text { limit }(\mu \mathrm{g} / \mathrm{L})\end{array}$ & $\begin{array}{l}\text { Measured } \\
\text { range }(\mu \mathrm{g} / \mathrm{L})\end{array}$ \\
\hline $\mathrm{Cd}$ & $0.22 \pm 0.04$ & 0.13 & $<\mathrm{dl}-8$ \\
$\mathrm{~Pb}$ & $5.60 \pm 0.97$ & 2.90 & $<\mathrm{dl}-75$ \\
$\mathrm{Mn}$ & $9.66 \pm 2.60$ & 7.81 & $500-3000$ \\
$\mathrm{Fe}$ & $197 \pm 51$ & 155 & $13000-400000$ \\
$\mathrm{Co}$ & $0.28 \pm 0.13$ & 0.39 & $5-24$ \\
$\mathrm{Ni}$ & $77 \pm 6$ & 20 & $<\mathrm{dl}-500$ \\
$\mathrm{Cu}$ & $6.6 \pm 2$ & 6 & $<\mathrm{dl}-300$ \\
$\mathrm{Zn}$ & $173 \pm 61$ & 184 & $<\mathrm{dl}-1000$ \\
$\mathrm{As}$ & $0.14 \pm 0.05$ & 0.16 & $12-200$
\end{tabular}

TABLE IV

Blanks and detection limits for the DET gels (lab USTL)

\begin{tabular}{llll}
\hline Element & $\begin{array}{l}\text { DET blank } \\
(\mu \mathrm{g} / \mathrm{L})\end{array}$ & $\begin{array}{l}\text { Detection limit } \\
(\mu \mathrm{g} / \mathrm{L})\end{array}$ & $\begin{array}{l}\text { Measured range } \\
(\mu \mathrm{g} / \mathrm{L})\end{array}$ \\
\hline $\mathrm{Cd}$ & $0.23 \pm 0.02$ & 0.06 & $0.39-5.5$ \\
$\mathrm{~Pb}$ & $3.92 \pm 0.61$ & 1.83 & $10.2-78$ \\
$\mathrm{Mn}$ & $1.24 \pm 0.31$ & 0.93 & $125-2600$ \\
$\mathrm{Fe}$ & $476 \pm 73$ & 219 & $500-350000$ \\
$\mathrm{Co}$ & $0.26 \pm 0.19$ & 0.57 & $7-32$ \\
$\mathrm{Cu}$ & $14.7 \pm 0.21$ & 0.63 & $20-150$ \\
$\mathrm{Zn}$ & $39 \pm 4.4$ & 13.2 & $52-523$ \\
$\mathrm{Cr}$ & $4.9 \pm 2.1$ & 6.3 & $32-900$ \\
\hline
\end{tabular}
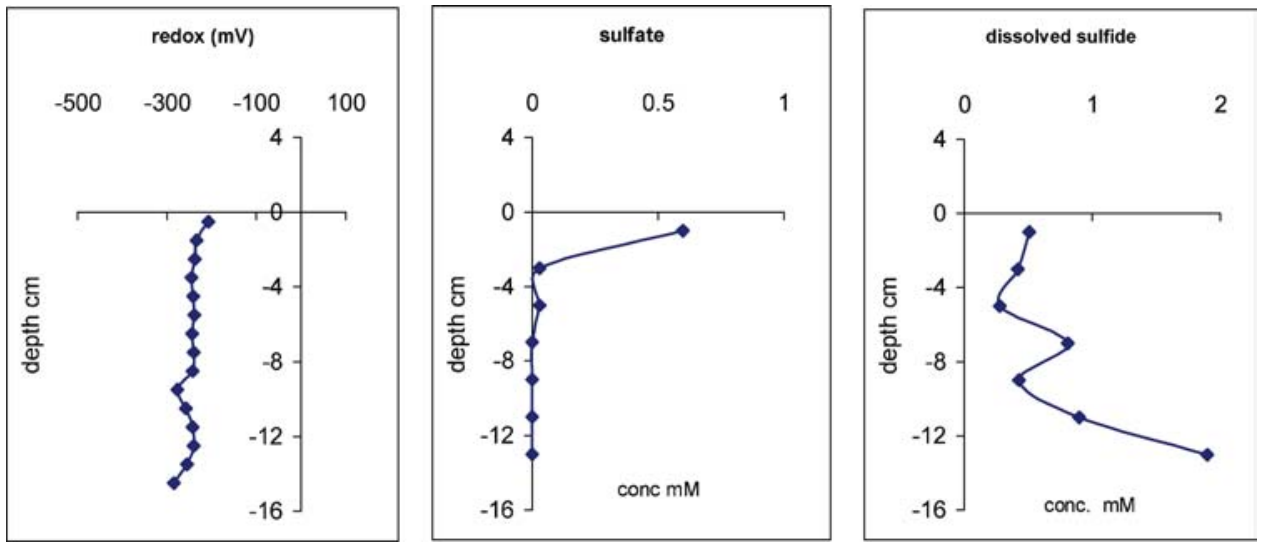

Figure 2. Redox potential, sulfate and sulfide concentrations in the pore waters of the sediments of the Rupel River. 


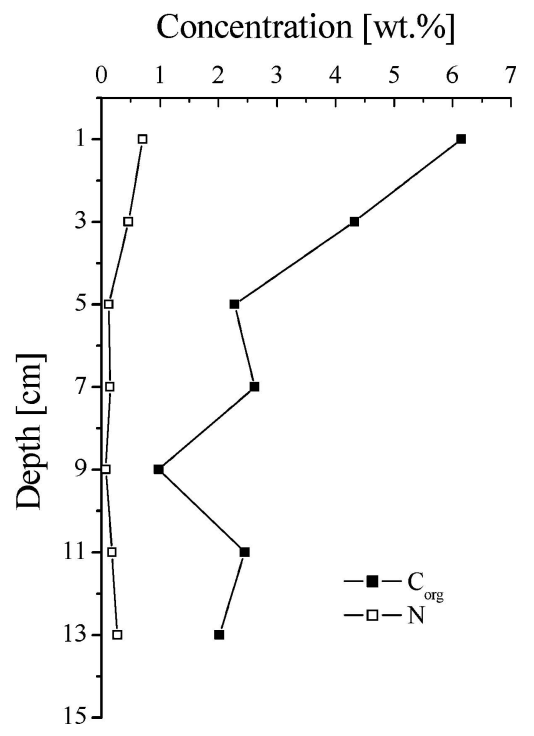

Figure 3. Concentration of organic $\mathrm{C}$ and $\mathrm{N}$ in the sediment of Rupel River.

The sediments were enriched in organic matter, with organic $\mathrm{C}$ (SOC) ranging up to $6.1 \mathrm{wt} . \%$ in the surface layer of the sediment (Figure 3).

The enrichment of organic matter with sulfur during earliest stages of diagenesis has been amply documented in marine sediments (Wakeham et al. 1995; Brüchert and Pratt, 1996; Werne et al., 2000; Amrani et al., 2004), while the importance of such reactions in freshwater environments is not very much appreciated (Urban et al., 1999). However, recent studies of lacustrine and soil organic matter, especially humic and fulvic acids, showed that their sulfur containing functional groups play an important role in the binding and immobilization of metals (Hutchinson et al., 2001). In the sediment of Rupel River, the organic S component is absolutely prevailing over inorganic $\mathrm{S}$ forms, which is typical for freshwater sediments (Gerritse, 1999). A good correlation $\left(R^{2}>0.99\right.$, with one outlier) exists between concentrations of organic carbon and organic sulfur in the sediment, indicating that the accumulation of biosynthetic and diagenetic organic sulfur is predominantly tied to the fluxes of organic matter (Suits and Arthur, 2000). The largest fraction (72-83\%, Figure 4) of total $S$ is bond to fulvic acids, while the humic $S$ fraction represents generally less than $1 \%$ of total S. Relatively high fulvic-to-humic acid ratio compared to soils is typical for sewage sludge (Gascó et al., 2004), which is to a large extent present in the sediment of Rupel River. These results are also in line with observations by Brüchert (1998) and Klavins and Apsite (1997), who found that humic acids contain higher amounts of $\mathrm{C}$ than fulvic ones, especially in eutrophic environments, and that the $\mathrm{S}: \mathrm{C}$ ratio in fulvic acids by far exceeds the $\mathrm{S}: \mathrm{C}$ ratio in humic acids. 


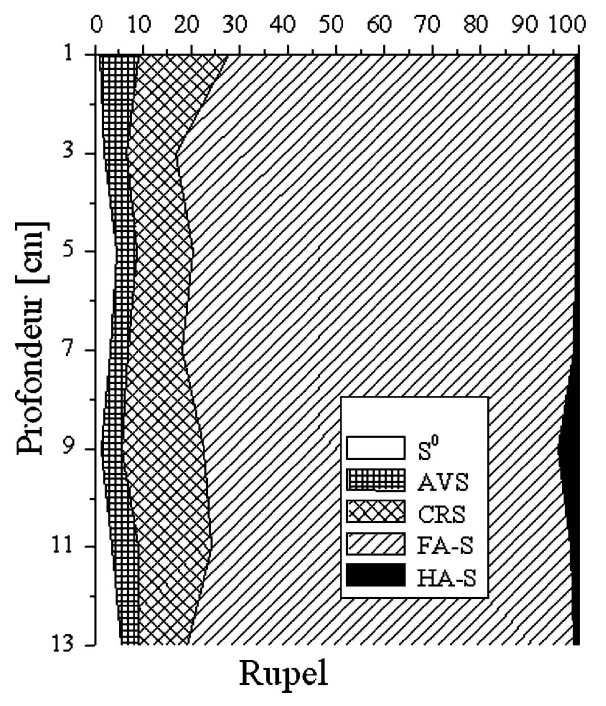

Figure 4. Relative distribution of the different S species in the sediments of the Rupel River (Acid Volatile Sulfides (AVS), Chromium Reducible Sulfur (CRS), elemental sulfur ( $\mathrm{S}^{\circ}$ ), HA humic matter, HA-S sulfur bound to humic matter, FA-S sulfur bound to fulvic acids).

Among inorganic $\mathrm{S}$ forms, CRS prevails over AVS and elemental S, with AVS/CRS ratio between 0.23 and 0.44 (Figure 4). AVS/CRS ratio is in good correlation with SOC $\left(R^{2}=0.71\right)$ and the lowest AVS/CRS ratio coincides with the lowest SOC concentration, indicating that formation of CRS, depends rather on the availability of organic matter for degradation by sulfate reduction than the availability of reactive Fe. Concentration of elemental $\mathrm{S}$ below $5 \mathrm{~cm}$ depth is similar or even larger than AVS concentration, indicating that the pyrite formation is driven by sulfide production and is formed rather by direct reaction of Fe hydroxides with $\mathrm{H}_{2} \mathrm{~S}$ than by conversion of AVS to CRS by addition of elemental S (Lein et al., 2002; Neretin et al., 2004).

\section{DET and DGT Profiles}

In core A a DGT probe and DET probe were placed back to back. The results of the DET profiles are shown in Figure 5 together with the results of pore water profiles obtained by centrifugation on a separate core. Although the concentrations of the trace metals $\mathrm{Cd}, \mathrm{Pb}, \mathrm{Zn}, \mathrm{Ni}$, and $\mathrm{Cu}$ obtained by DET are less reliable due to the blank values of the gel, their profiles are included in the graphs as they show specific features and correlations among the elements.

The profiles of $\mathrm{Mn}$ and $\mathrm{Fe}$ show the reductive mobilization of these metals just below the sediment water interface in accordance to the redox profile. Fe concentrations remain elevated up to $-12 \mathrm{~cm}$, then they decrease. This decrease corresponds to an increase in dissolved sulfide concentrations. DET profiles of $\mathrm{Fe}$ 

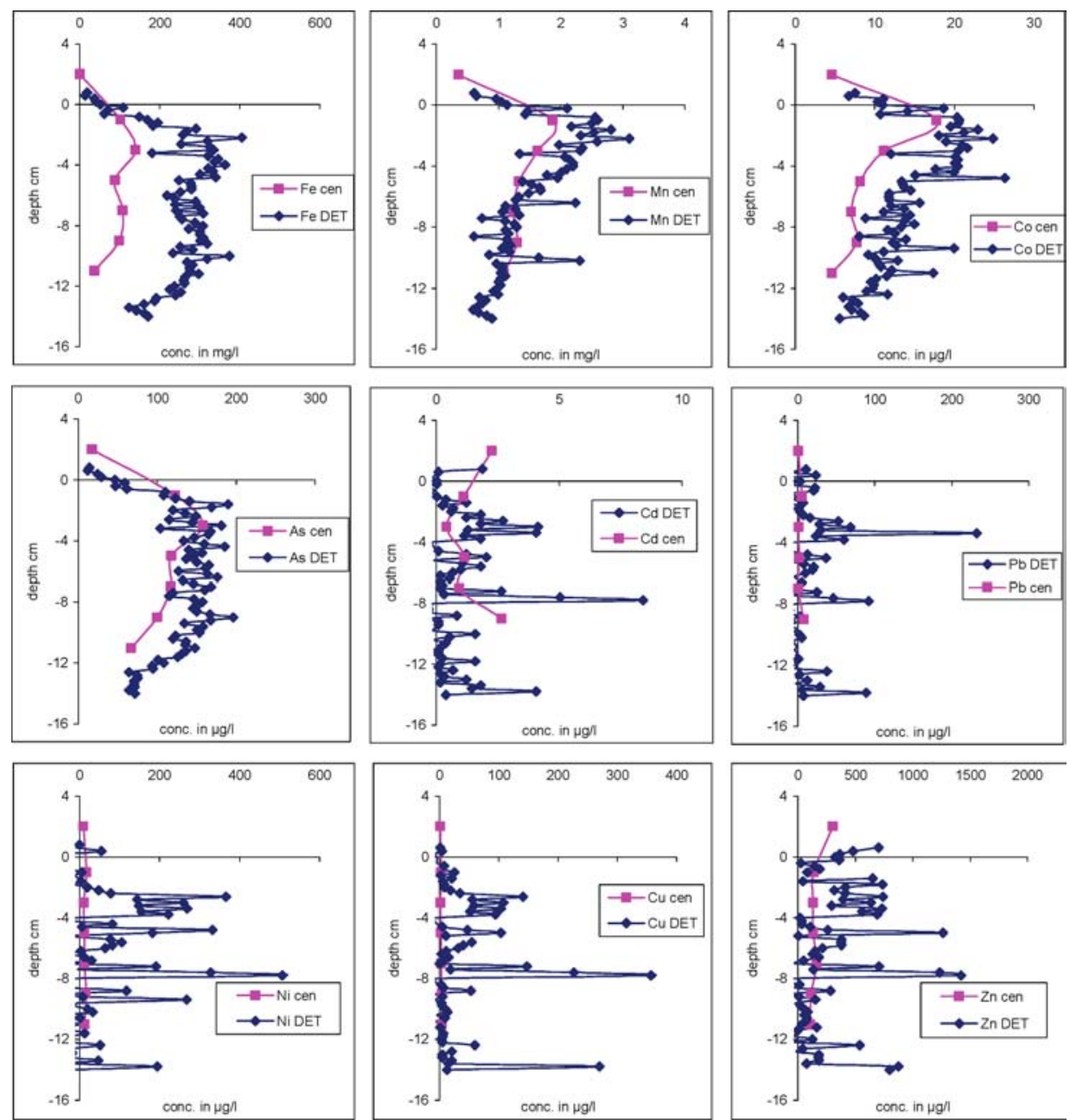

Figure 5. Core A DET profile and metal concentrations obtained by centrifugation on a separate core.

and As are well correlated as well as those of $\mathrm{Mn}$ and $\mathrm{Co}$. Mobilization of $\mathrm{Cd}, \mathrm{Pb}$, $\mathrm{Cu}, \mathrm{Ni}$ and $\mathrm{Zn}$ is also linked to the reduction of $\mathrm{Fe}$ and $\mathrm{Mn}$ but is also governed by other processes. A pronounced maxima at $-8 \mathrm{~cm}$ is observed as well as an increase in these trace metals at the sediment water interface.

The DGT concentration profiles and fluxes are shown in Figure 6. The DGT technique gives a direct measurement of time averaged fluxes rather than concentrations. Concentrations can be estimated assuming a constant pore water concentration; that is a sufficiently fast resupply from the solid phase. The fluxes of Co and $\mathrm{As}$ are related to the reductive mobilization of $\mathrm{Fe}$ and $\mathrm{Mn} . \mathrm{Pb}, \mathrm{Cd}, \mathrm{Ni}, \mathrm{Cu}$ and $\mathrm{Zn}$ show a pronounced maxima at the sediment surface. An increase in $\mathrm{Ni}, \mathrm{Pb}, \mathrm{Cd}$, $\mathrm{Cu}$ and $\mathrm{Zn}$ can also be observed in the zone of $\mathrm{Fe}$ and $\mathrm{Mn}$ reduction as well as at 

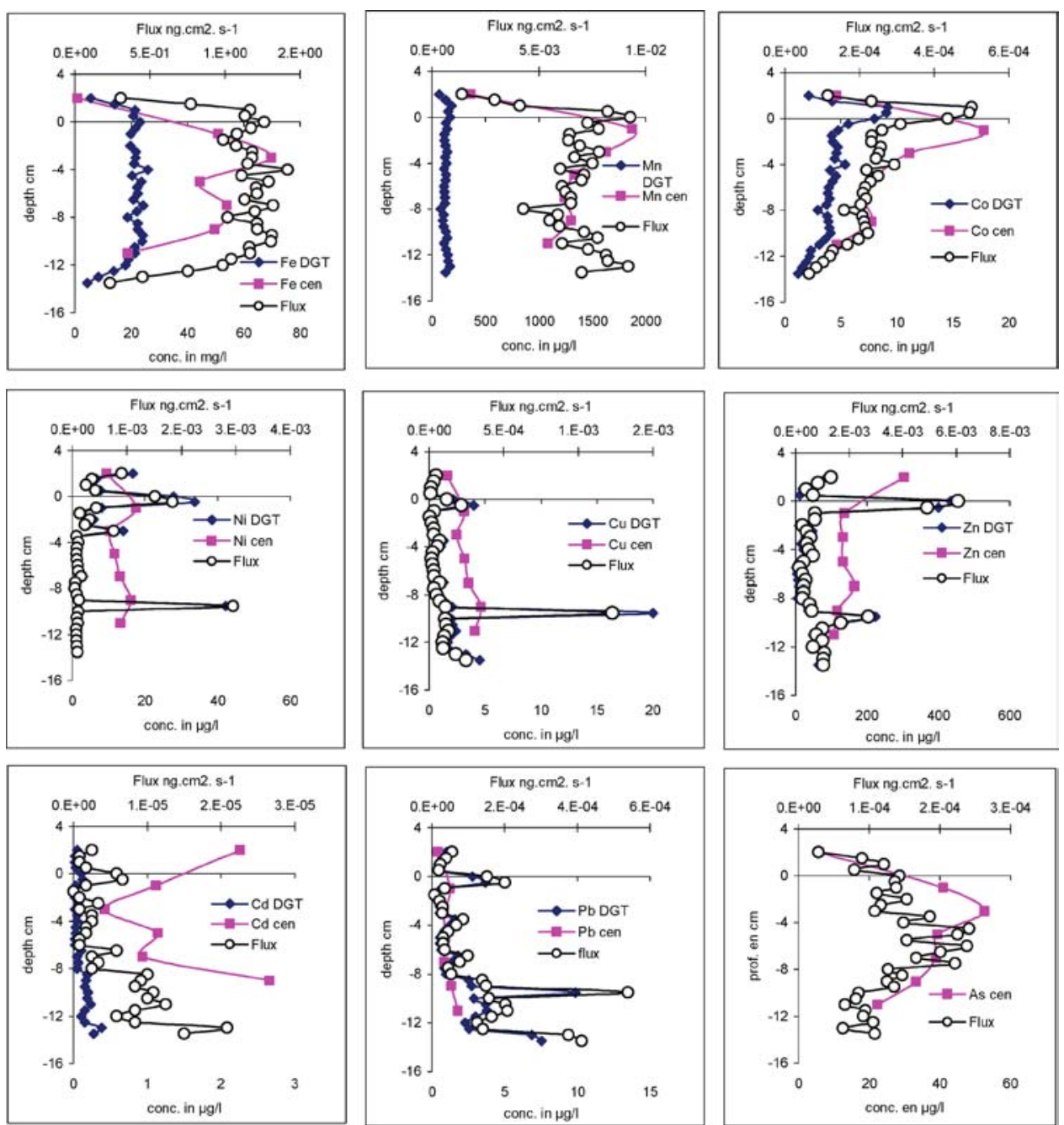

Figure 6. Core A DGT concentration profile and fluxes and pore water concentrations obtained by centrifugation on a separate core.

around $-8 \mathrm{~cm}$. At the same depth an important increase in the DET concentrations of these elements was also observed.

Comparing the concentrations obtained by centrifugation and the DGT concentrations we see that for Fe the DGT concentrations are a factor 3 lower than the centrifugation data (a factor 10 lower than the DET concentrations); for Mn the DGT concentrations are a factor 10 lower, a factor 2-5 lower for the metals $\mathrm{Co}, \mathrm{Ni}, \mathrm{Cu}$, and $\mathrm{Zn}$ (with the exception of the surface maxima where the DGT concentrations are higher) and a factor 10 lower for $\mathrm{Cd}$. Only for $\mathrm{Pb}$ the concentrations obtained by DGT and centrifugation are comparable. For As no DGT concentrations were 

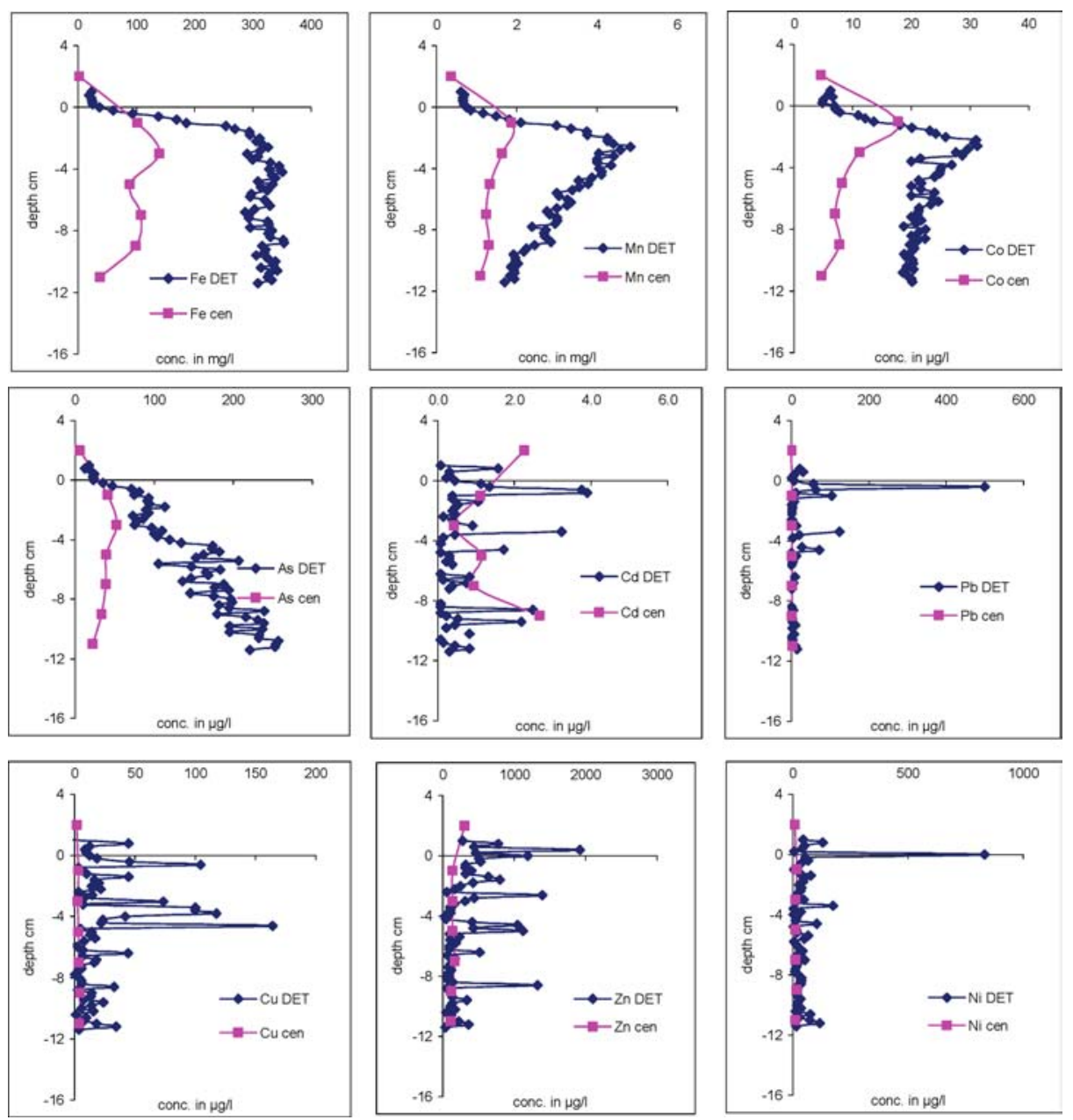

Figure 7. Core B DET profile and metal concentrations obtained by centrifugation on a separate core.

calculated as the diffusion coefficient for As is not available but the profile of the fluxes is in good agreement with the centrifugation profile.

Spatial (lateral) heterogeneity is apparent when we compare the DET and DGT profiles of core B with the centrifugation profiles (Figures 7 and 8). DET concentrations of $\mathrm{Mn}, \mathrm{Co}$ and As in core B are higher than in core A and higher than the centrifugation concentrations. The As profile increase with depth and does not show the characteristic correlation with Fe both in the DET and DGT profiles. The trace metals show an important surface maximum in both DET and DGT profiles. Similar concentration differences between DGT and centrifugation are observed as with core $\mathrm{A}$ with the largest differences observed for $\mathrm{Cd}$ and $\mathrm{Mn}$; the lowest for $\mathrm{Co}$ and $\mathrm{Pb}$ and intermediate behavior for the other trace metals. 

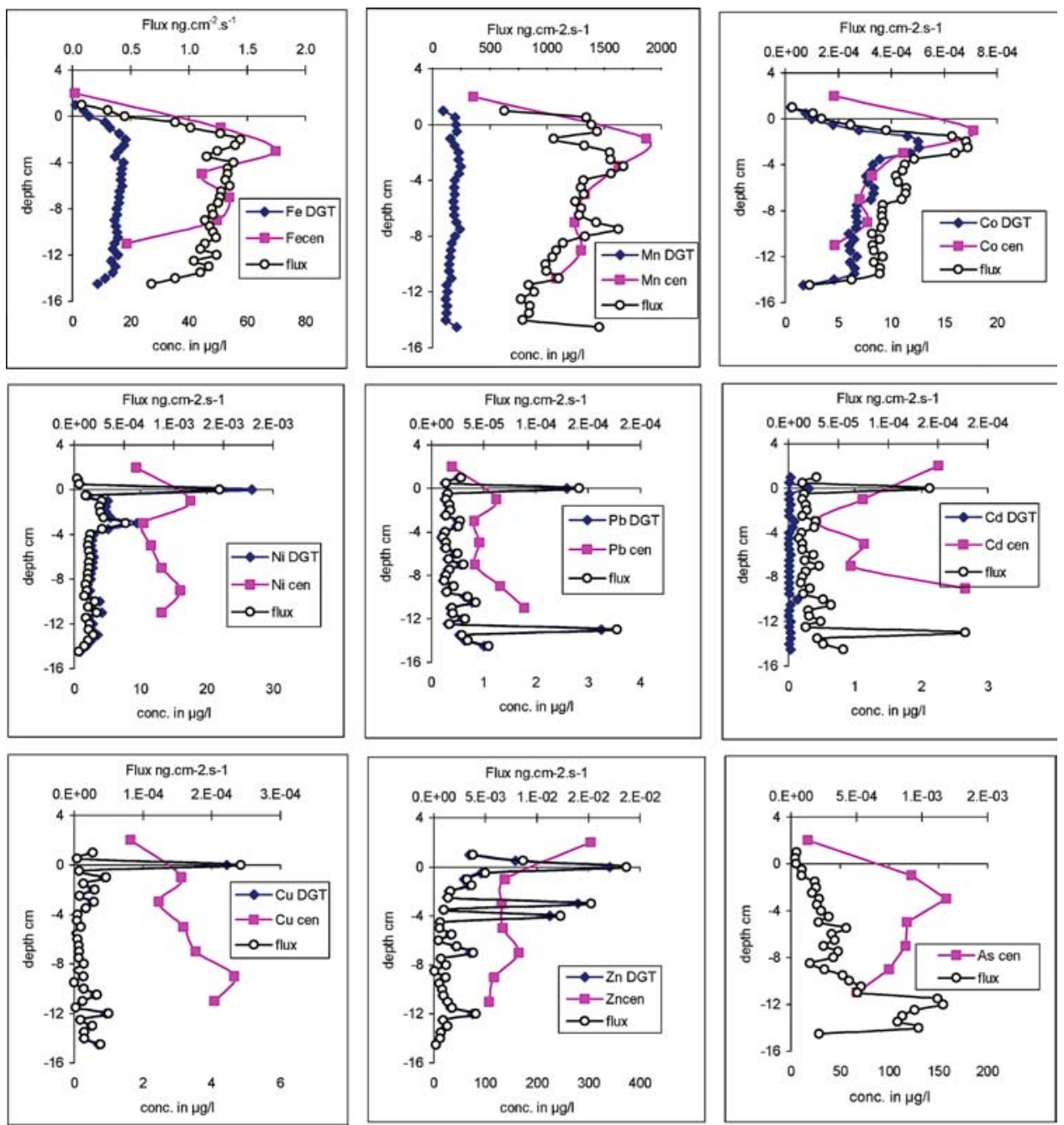

Figure 8. Core B DGT concentration profile and fluxes and pore water concentrations obtained by centrifugation on a separate core.

The ratio of the average concentrations obtained by DGT (averaging depth profiles and both cores) and the DET profiles for $\mathrm{Fe}$ and $\mathrm{Mn}$ and the centrifugation profiles for the trace elements ( $R$ values) gives us the following order of mobilizable trace metals: $\mathrm{Pb}(R=0.9), \mathrm{Zn}(R=0.72), \mathrm{Co}(R=0.42), \mathrm{Ni}(R=0.39), \mathrm{Cu}$ $(R=0.35), \operatorname{Mn}(R=0.1) \%, \mathrm{Fe}(R=0.08), \mathrm{Cd}(R=0.04)$.

To verify whether concentrations based on DGT measurements may be calculated, in core 32 DGT probes were placed with different diffusive gel thickness. In the fully sustained case, concentrations calculate with the two gels will be the same; if the diffusion limited, or only a partial resupply from the solid phase concentrations 

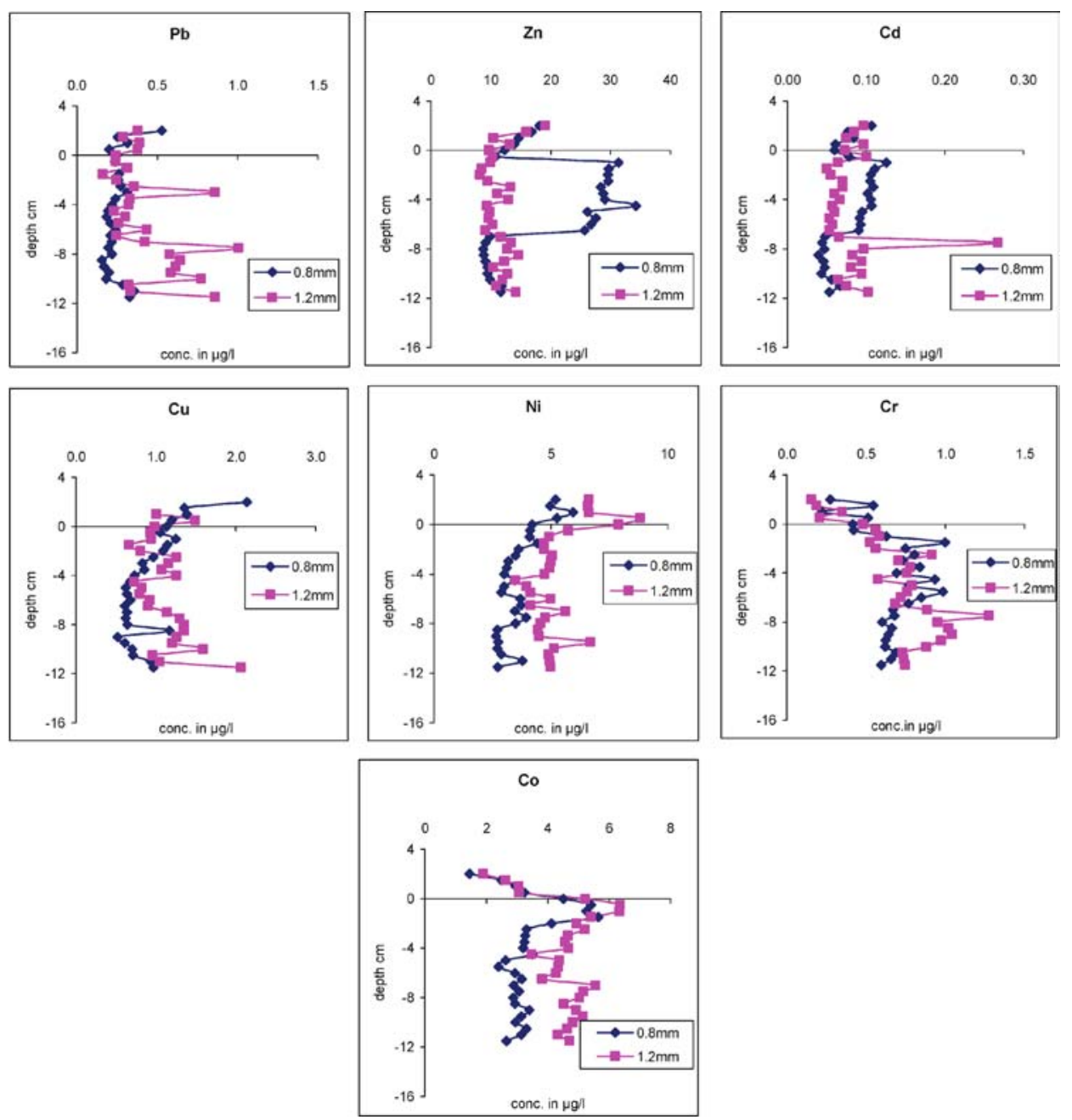

Figure 9. DGT concentration profiles of core C. Two DGT probes with gel thickness of $0.8 \mathrm{~mm}$ and $1.2 \mathrm{~mm}$ were placed back to back.

in the thinner gel will be underestimated. If the flux is diffusion limited the ratio of the concentrations obtained by the two gels should be equal to the ration of the gel thicknesses, thus 1.5 .

Figure 9 shows that only significantly higher concentrations for the thicker gel (below the sediment surface) are only observed for $\mathrm{Co}$ and $\mathrm{Ni}$. $\mathrm{Cu}, \mathrm{Zn}, \mathrm{Cd}$ and $\mathrm{Pb}$ do not show systematic higher concentrations in the thick gel. Local heterogeneity, even within the same core, account for differences in the profiles. A significant increase in $\mathrm{Zn}$ and $\mathrm{Cd}$ in the section 0-6 $\mathrm{cm}$ depth was observed in the $0.8 \mathrm{~mm}$ probe.

The DET profiles of core D (Fig 10) show on a broad scale that the elements Co, $\mathrm{Cd}, \mathrm{Pb}, \mathrm{Cu}$ and $\mathrm{Zn}$ are linked to the reductive dissolution of $\mathrm{Fe}$ and $\mathrm{Mn}$; however 

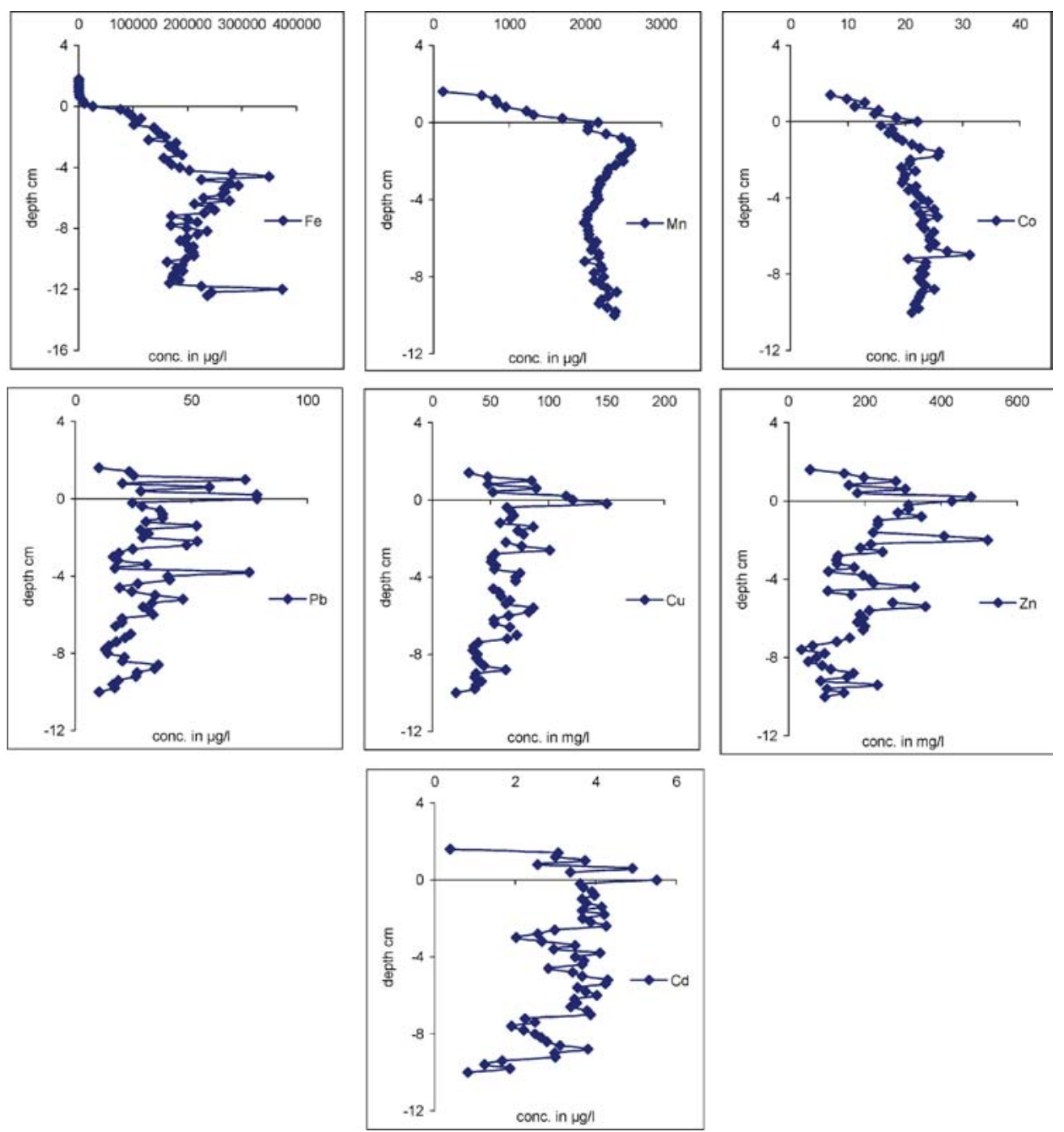

Figure 10. CORE D DET profile.

$\mathrm{Cd}, \mathrm{Cu}, \mathrm{Zn}, \mathrm{Pb}$ and to a lesser extend $\mathrm{Co}$ show an increase between -3 and $-8 \mathrm{~cm}$ not directly linked to the $\mathrm{Mn}$ profile. In addition, surface maxima are observed for $\mathrm{Pb}, \mathrm{Cd}, \mathrm{Cu}$ and $\mathrm{Zn}$.

\section{Metal Profiles in the Sediment Phase}

The total concentration of metals in the sediment phase is shown in Figure 11. The metal concentrations in the sediments exceed the background levels for uncontaminated sediments in Flemish rivers by far. Background values are, (expressed in $\mu \mathrm{g} / \mathrm{g}$ ), 0.38 for $\mathrm{Cd}, 14$ for $\mathrm{Pb}, 67$ for $\mathrm{Zn}, 11$ for $\mathrm{Ni}$ and $8 \mathrm{for} \mathrm{Cu}$ (VMM ref website). The concentrations of Fe and Mn decrease with depth, probably due to reductive 

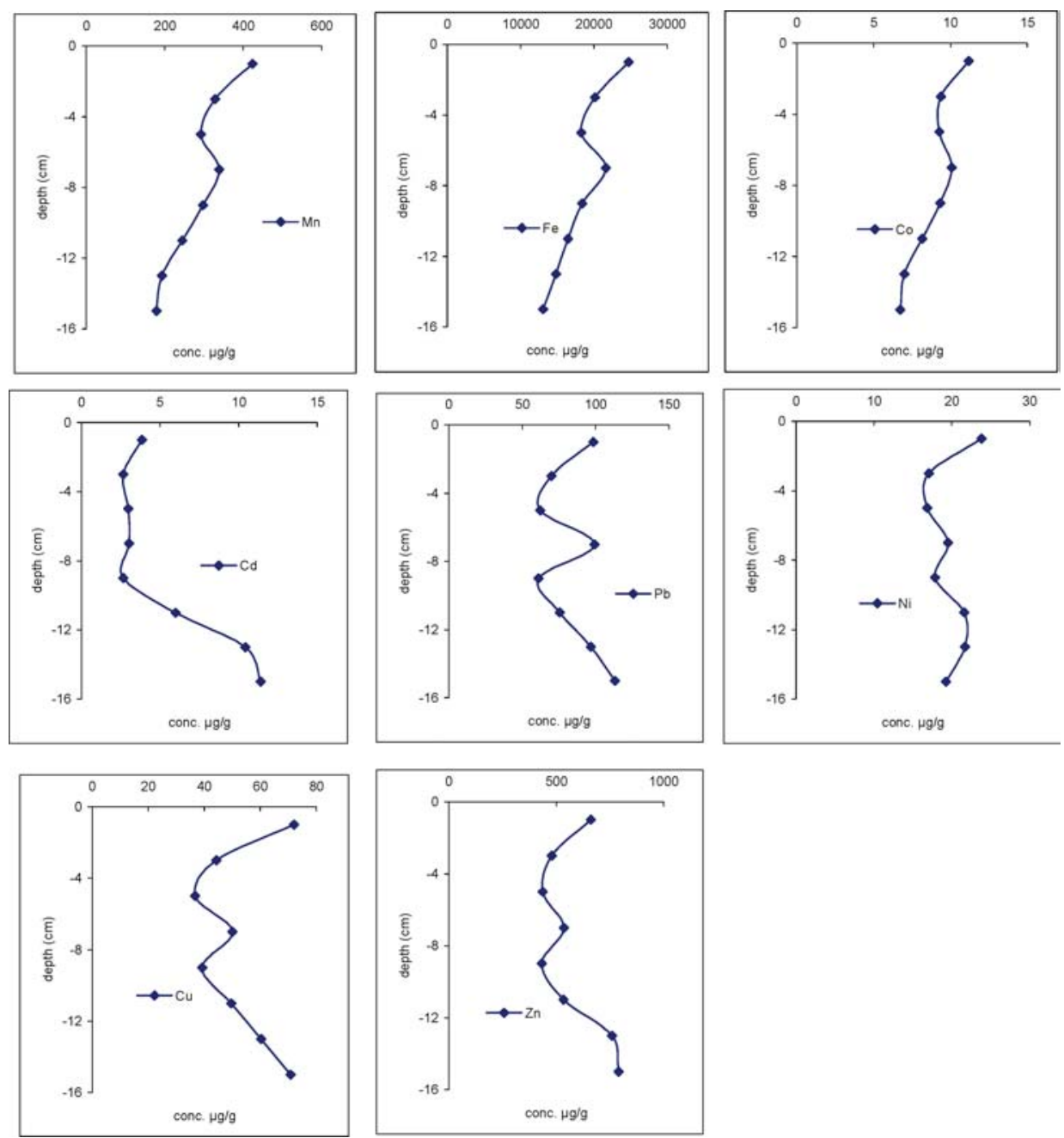

Figure 11. Metal profiles in the sediment phase.

mobilization; Co and to a lesser extend Ni follows this trend whereas the metals $\mathrm{Cd}, \mathrm{Pb}, \mathrm{Cu}$ and $\mathrm{Zn}$ show a decrease in the first $4 \mathrm{~cm}$ and an increase with depth below $9 \mathrm{~cm}$. This follows the pattern of AVS/CRS and the dissolved sulfides and is probably due to the precipitation of these metals as sulfides.

\section{Discussion}

\section{INTERLABORATORY COMPARISON}

In general for all elements a good agreement is observed between the data obtained by the two labs. The detection limits of both labs are comparable and the obtained 

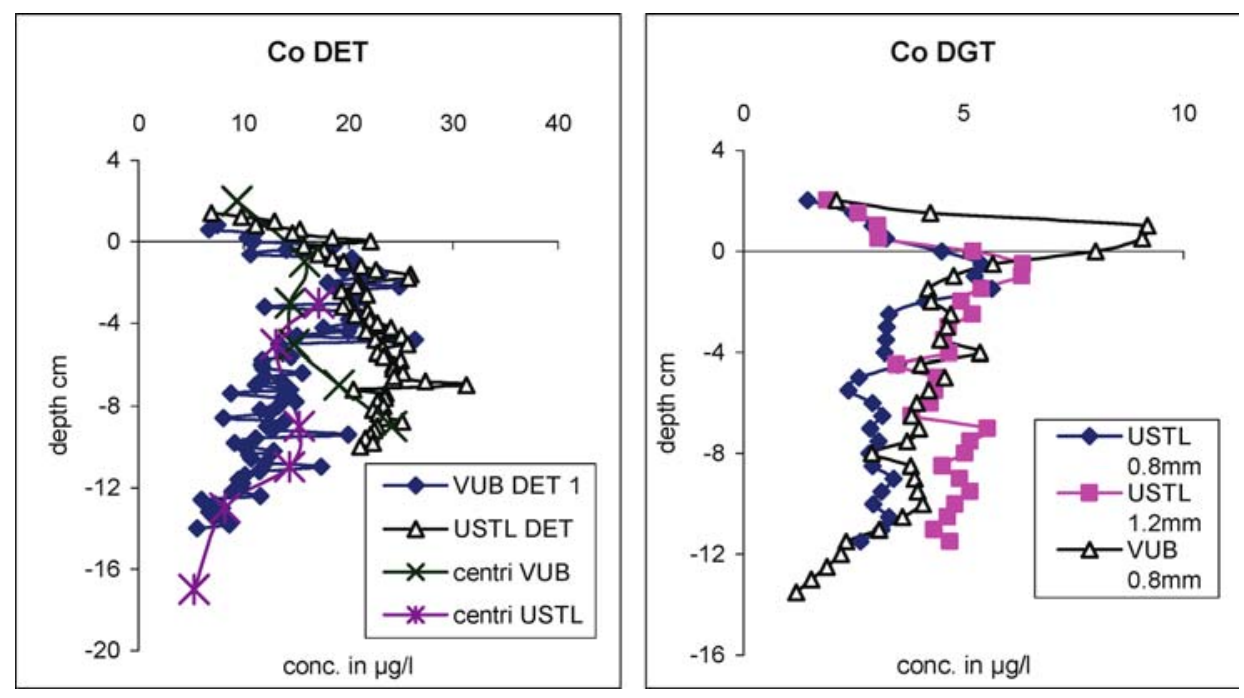

Figure 12. Comparison of concentration profiles of Co obtained by the two labs.

profiles are in good agreement taking the spatial variability into account. As an example Figure 12 shows the profiles obtained for Co by centrifugation, DET and DGT for the two labs.

\section{Fe CONCENTRATIONS BY CENTRIFUGATION AND DET}

In general a good agreement in concentration ranges (taking the lateral variability into account) between DET and centrifugation can be observed for the elements which are easily quantified by DET (Fe, Mn, Co, As) except for Fe where $\mathrm{Fe}$ concentrations obtained by centrifugation are systematically lower (Figure 13). We have also observed this in the Upper Scheldt sediments (unpublished data). This is either due to an overestimation of the DET results, an underestimation of the centrifugation results, or both. Overestimated DET profiles may be due to: a) an increased bacterial activity (Fe reduction) due to deployment of the gels at room temperature or b) precipitation of colloidal $\mathrm{Fe}$ oxyhydroxides in the gels followed by the establishment of a new equilibrium between gel and pore water (Davison et al., 2000). The latter can normally only occur when the gels are not properly deoxygenated before deployment which was not the case. A possible explanation for the lower results obtained by centrifugation is the coagulation and precipitation of colloidal Fe in the centrifugation step or filtration step. Further experiments are currently being performed to investigate this phenomenon. 


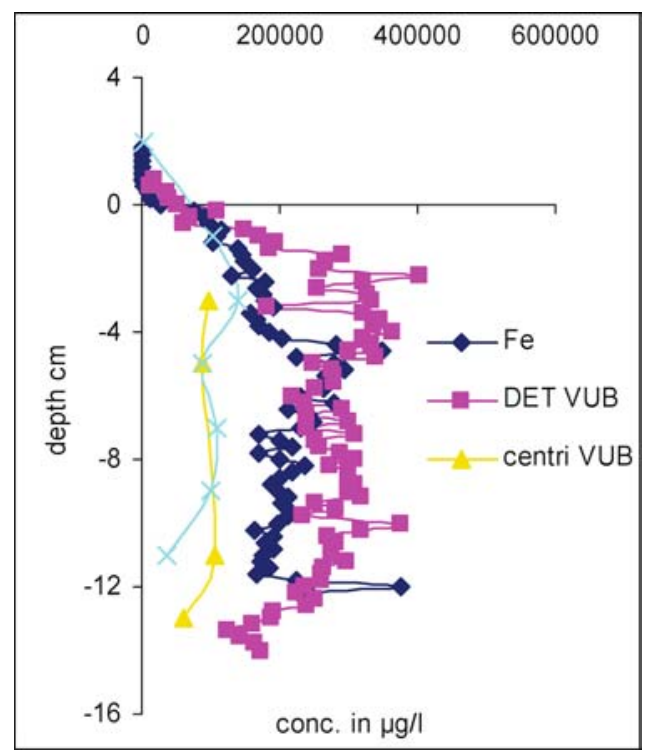

Figure 13. Comparison of Fe concentrations obtained by DET (by the two labs) and centrifugation (by the two labs).

\section{TRACE METAL MOBILITY AND SPECIATION}

Two factors are responsible for the differences in concentrations observed by DET (or centrifugation) and DGT: 1) there is insufficient resupply from the solid phase to sustain the flux to the resin gel due to the tight binding on the metals on the solid phase (precipitation rather than adsorption) and 2) the metals are complexed to large organic molecules (humic and fulvic acids); the porosity of the DET gels is much larger than the DGT gels, thus limiting the diffusion in the DGT gels to smaller labile complexes.

The order of lability of the metals is $\mathrm{Pb}>\mathrm{Zn}>\mathrm{Co}>\mathrm{Ni}>\mathrm{Cu}>\mathrm{Mn}>\mathrm{Fe}>$ $\mathrm{Cd}$. This order cannot be explained by the stability of the metal organic complexes or by the solubility of the metal sulfides. CuS is the least soluble of these metals (Ks $8.510^{-45}$ ) and the solubility of $\mathrm{CdS}$ and $\mathrm{PbS}$ are comparable (respectively 1 $10^{-28}$ and $710^{-28}$ ).

The ratio of the DGT concentrations to the total pore water concentrations ( $\mathrm{R}$ values) are: $\mathrm{Pb}(R=0.9), \mathrm{Zn}(R=0.72), \mathrm{Co}(R=0.42), \mathrm{Ni}(R=0.39), \mathrm{Cu}$ $(R=0.35), \mathrm{Mn}(R=0.1) \%, \mathrm{Fe}(R=0.08), \mathrm{Cd}(R=0.04)$. Especially the very low values found for $\mathrm{Cd}$ are in contrast to results observed in other studies. $\mathrm{Cd}$ is generally considered to be a labile element. A $R$ ratio of 0.95 has been reported by Zhang et al. for sediments of Esthwait Water (Zhang et al., 1995). In the Rupel samples $\mathrm{Cd}$ appears to be bound to phases with very low mobility (incorporated in pyrite, strong organic matter associations ... ). In addition under anoxic conditions 
Cd can form soluble sulfides which will not be bound to Chelex $\left(\mathrm{CdHS}^{+}, \mathrm{Cd}(\mathrm{HS})_{2}\right.$, ...). $\mathrm{Pb}$ and $\mathrm{Zn}$ show high $R$ ratios and are probably adsorbed to phases such as oxides and sulfides and are rapidly desorbed when the pore waters become depleted in the vicinity of the gel. $\mathrm{Co}, \mathrm{Ni}$ and $\mathrm{Cu}$ are partially resupplied from the solid phase. The close relationship between the profiles of these elements and Fe and Mn show that the mobility of these elements are tightly linked to the reductive dissolution of $\mathrm{Fe}$ and $\mathrm{Mn}$. The mobilization of As is also tightly linked to the reduction of $\mathrm{Fe}^{3+}$. Under oxic conditions As in the dissolved phase will predominantly be present as an anion $\left(\mathrm{AsO}^{-2}\right)$ and will not be bound to Chelex. Under anoxic conditions As will be mobilized from the solid phase as arsenate (As3+) and this form will readily bound to Chelex. The DET and DGT As profile of core B shows that As is not only controlled by the redox behavior of $\mathrm{Fe}$ but may also be released from other sedimentary phases such as sulfides $\left(\mathrm{As}_{2} \mathrm{~S}_{3}\right)$. The low $R$ ratios for Fe and Mn suggest a tight binding of these metals to the sediment phase, slow mobilization kinetics and/or the presence of colloidial forms of Fe in the pore waters which are not bound to Chelex or the complexation with large organic complexes (humic acids, fulvic acids).

The metals $\mathrm{Cu}, \mathrm{Zn}, \mathrm{Cd}, \mathrm{Pb}$ and $\mathrm{Ni}$ also show a pronounced surface maximum. This maximum has already been observed in several studies and can be attributed to the mobilization of these metals from the decomposition of freshly precipitated organic matter (Hamilton-Taylor et al., 1996; Zhang et al., 1995). Very sharp surface maxima are found at $\mathrm{mm}$ scale which cannot be observed with conventional pore water extraction techniques. The very high concentrations observed at the sediment-water interface are an important source of these metals to the overlying water.

\section{Conclusions}

Using the techniques of DET and DGT high resolution profiles of total and labile metal species in pore water could be established. The application of the DET technique is limited by the blank values of the gel, the absence of preconcentration and the necessity to dilute the samples before analysis. We are currently testing cleaning procedures for the agarose gel.

The DGT technique provides information on both the labile metal fraction as the mobility of the sediment bound metals. Important interelement relationships can be found.

The sediments show a strong lateral heterogeneity, which complicates comparisons between the cores and thus the comparison between the total metal concentrations obtained by centrifugation and the DGT profiles.

The high metal concentrations at the sediment water interface at mm intervals show the necessity to perform high resolution profiles in order to identify the underlying processes and to establish benthic fluxes. 


\section{Acknowledgements}

The work was carried out in the framework of the EU- INTERREG III- STARDUST project and the authors wish to thank the project managers for their financial support. The authors also wish to thank the European Copper Institute and International Copper Association for their financial support.

\section{References}

Amrani, A. and Aizenshtat, Z.: 2004, 'Mechanisms of sulfur introduction chemically controlled: $\delta^{34} \mathrm{~S}$ print', Org. Geochem. 35, 11-12, 1319-1336.

Billon, G., Ouddane, B. and Boughriet, A.: 2001a, 'Artefacts in the speciation of sulfides in anoxic sediments', Analyst 126, 1805-1809.

Billon, G., Ouddane, B., Laureyns, J. and Boughriet, A.: 2001b, 'Chemistry of metal sulfides in anoxic sediments', Phys. Chem. Chem. Phys. 3, 3586-3592.

Brüchert, V.: 1998, 'Early diagenesis of sulfur in estuarine sediments: The role of sedimentary humic and fulvic acids', Geochim. Cosmochim. Acta 62, 1567-1586.

Davison, W., Grime, G. W., Morgan, J. A. and Clarke, K.: 1991, 'Distribution of dissolved iron in sediment pore waters at submillimeter resolution', Nature 352, 323-324.

Davison, W., Fones, G. and Grime, G.: 1997, 'Dissolved metals in surface sediment and a microbial mat at $100 \mu \mathrm{m}$ resolution', Nature $\mathbf{3 8 7}, 885-888$.

Davison, W., Fones, G., Harper, M., Teasdale, P. and Zhang, H.: 2000, 'Dialysis, DET and DGT: In situ diffusional techniques for studying water, sediments and soils', in In Situ Moniotoring of Aquatic Systems: Chemical Analysis and Speciation, Wiley, Chichester, pp. 495-570.

Docekalova, H., Clarisse, O., Salomon, S., and Wartel, M.: 2002, 'Use of constrained DET probe for a high-resolution determination of metals and anions distribution in the sediment pore water', Talanta 57, 145-155.

Fones, G., Davison, R. W. and Hamilton-Taylor, J.: 2004, 'The fine scale remobilization of metals in the surface sediment of the North-East Atlantic', Cont. Shelf Res. 24, 1485-1504.

Gascó, G., Martinez-Iñigo, M. J. and Lobo, M. C.: 2004, 'Soil organic matter transformation after a sewage sludge application', Electron. J. Environ. Agric. Food Chem. 3(4).

Gerritse, R.: 1999, 'Sulfur, organic carbon and iron relationships in estuarine and freshwater sediments: Effects of sedimentation rate', Appl. Geochem. 14, 41-52.

Hamilton-Taylor, J., Davison, W. and Morfette, K.: 1996, 'The biogeochemical cycling of Zn and Cu in a seasonally anoxic lake', Limnol. Oceanogr. 41(3), 408-418.

Henneke, E. Luther III, G. W., de Lange, G. J. and Hoefs, J.: 1997, 'Sulfur speciation in anoxic hypersaline sediments from the eastern Mediterranean Sea', Geochim. Cosmochim. Acta 61, 307-321.

Klavins, M. and Apsite, E.: 1997, 'Sedimentary humic substances from Lakes in Latvia', Environ. Int. 23, 783-790.

Lein, A., Pimenov, N., Guillou, C., Martin, J.-M., Lancelot, C., Rusanov, I., Yusupov, S., Miller, Y. and Ivanov, M.: 2002, 'Seasonal dynamics of the sulphate reduction rate on the North-western Black Sea shelf', Estuar. Coast. Shelf Sci. 54, 385-401.

Neretin, L. N., Böttcher, M. E., Jørgensen, B. B., Volkov, I. I., Lüscher, H. and Hilgenfeldt, K.: 2004, 'Pyritization process and greigite formation in the advancing sulfidization front in the upper Pleistocene sediments of the Black Sea', Geochim. Cosmochim. Acta 68, 2081-2093.

Panutrakul, S., Monteny, F. and Baeyens, W.: 2001, 'Seasonal variations in sediment sulfur cycling in the Ballastplaat mudflat, Belgium', Estuaries 24(2), 257-265. 
Standard methods for the examination of water and wastewater. $4500-\mathrm{SO}_{4}^{2-}$ : Ion-Selective Electrode Method. Ceseri, L. S., Greenberg, A. E., Eaton, A.D. (eds.), 20th edition, APHA, AWWA \& WEF, 1998, US.

Suits, N. S. and Arthur, M. A.: 2000, 'Sulfur diagenesis and partitioning in Holocene Peru shelf and upper slope sediments', Chem. Geol. 163, 219-234.

Urban, N. R., Ernst, K. and Bernasconi, S.: 1999, 'Addition of sulfur to organic matter during early diagenesis of lake sediments', Geochim. Cosmochim. Acta 63, 837-853.

Wakeham, S. G., Sinninghe, Damsté, J. S., Kohnen, M. E. L. and de Leeuw, J. W.: 1995, 'Organic sulfur compounds formed during early diagenesis in Black Sea sediments', Geochim Cosmochim Acta 59, 521-533.

Werne, J. P., Lyons, T. W., Hollander, D. J., Formolo, M.J. and Sinninghe, Damsté J. S.: 2003, 'Reduced sulfur in euxinic sediments of the Cariaco Basin: Sulfur isotope constraints on organic sulfur formation', Chem. Geol. 195, 159-179.

Zhang, H. and Davison, W.: 1995, 'Performance characteristics of diffusion gradients in thin-films for the in-situ measurement of trace metals in aqueous solutions', Anal. Chem. 67(19), 3391-3400.

Zhang, H., Davison, W., Miller, S. and Tych, W.: 1995, 'In situ high resolution measurements of fluxes of $\mathrm{Ni}, \mathrm{Cu}, \mathrm{Fe}$ and $\mathrm{Mn}$ and concentrations of $\mathrm{Zn}$ and $\mathrm{Cd}$ in porewaters by DGT', Geochim. Cosmochim. Acta 59(20), 4181-4192. 